\title{
The distances covered by basketball referees in a match increase throughout the competition phases, with no change in physiological demand
}

This article was published in the following Dove Press journal:

Open Access Journal of Sports Medicine

13 August 2013

Number of times this article has been viewed

\author{
João Paulo Borin' \\ José Francisco Daniel 2,3 \\ Valéria Bonganha ${ }^{3}$ \\ Anderson Marques \\ de Moraes 2,4 \\ Cláudia Regina Cavaglieri' \\ Luciano Allegretti \\ Mercadante ${ }^{5}$ \\ Marcos Tadeu Nolasco \\ da Silva ${ }^{6}$ \\ Paulo Cesar Montagner \\ 'School of Physical Education, \\ University of Campinas (UNICAMP), \\ Campinas, Brazil; ${ }^{2}$ Pontifical Catholic \\ University of Campinas, Campinas, \\ Brazil; ${ }^{3}$ Postgraduate Program in \\ Physical Education, ${ }^{4}$ Postgraduate \\ Program in Children's Health, \\ University of Campinas (UNICAMP), \\ Campinas, Brazil; ${ }^{5}$ School of Applied \\ Sciences, University of Campinas \\ (UNICAMP), Limeira, Brazil; ${ }^{6}$ School \\ of Medical Science, University of \\ Campinas (UNICAMP), Campinas, \\ Brazil
}

Correspondence: João Paulo Borin School of Physical Education, University of Campinas (UNICAMP), Av. Érico Veríssimo, 70I, CEP: |3083-85 |, Caixa Postal 6134, Campinas, Brazil Tel +55 I9 352I 6773

Email borinjp@fef.unicamp.br
Background: It is crucial to know the demands on basketball referees, in different match periods (MPs) and phases of competition, for planning referee training and subsequent successful refereeing.

Objective: To measure and evaluate the distance covered by referees in a match by measuring the number of interruptions, percentage of heart rate $(\% \mathrm{HR})$, and blood lactate concentration ([lac]) in different phases of competition and in different MPs.

Method: We studied the qualifying (QP), semifinal (SP), and final (FP) phases of a total of 12 matches (four matches in each phase) of the 2009-2010 Brazilian Basketball League. Distance covered, number of match interruptions, and referees' $\% \mathrm{HR}$ and [lac] were analyzed. We compared the results between competition phases and between MPs (1st MP, 2nd MP, 3rd MP, and 4th MP). Results: Regarding the distances covered, we observed significant differences $(P<0.05)$ in the 1st, 2nd, and 3rd MPs between the FP and the other two phases (SP and QP) throughout the match, between each phase; in the 4th MP, a significant difference was found when comparing the QP and the other two phases. Comparing the periods within each phase, we found that a greater distance was covered in the 4th MP in relation to the 3rd MP during the FP. No significant differences were found among the remaining variables.

Conclusion: The distances covered by referees in a basketball match increase throughout competition phases. This information is essential for planning of training and for the subsequent success of a referee.

Keywords: referees, basketball, distance covered, percentage of maximum heart rate

\section{Introduction}

Basketball is one of the most popular sports in the world. It has features specific to it, such as variety of movement, ${ }^{1}$ and its players must be highly capable in different capacities, such as aerobic capacity, anaerobic power, speed, agility, and muscle strength. ${ }^{2}$ For a game to develop as it should, the referees (three referees per match) must follow the game with full attention and precision control. The referees perform movements at different speeds, aiming at proper positioning on the basketball court. The ability of referees to respond to the physical and physiological demands imposed during a match is the key to refereeing success in many sports.,

There are few studies that have aimed to analyze the demands on referees in basketball matches, especially in relation to distance covered. We have found a single study, ${ }^{5}$ involving adult and youth basketball teams, that took place prior to a change in the rules, which consisted of a decrease in the time to attack from 30 to 24 seconds, and in the time to pass through the middle line of the court from 10 to 8 seconds, and a change from two periods 
of 20 minutes to four periods of 10 minutes. It was observed in this study that the basketball referee moved less than the player $(4,898 \mathrm{~m}$ versus $6,104 \mathrm{~m}) .{ }^{5}$ After the rule changes, there was an increase in the intensity of the game, ${ }^{6}$ but there are, to our knowledge, no studies concerning the distance covered by basketball referees during a game after these changes. The distance covered by referees in other sports, such as soccer, is approximately $10,000 \mathrm{~m}$ per game, and 7,500 $\mathrm{m}$ for the assistants, ${ }^{3}$ which, in a game of futsal, is 5,892 $\pm 5.64 \mathrm{~m} .^{7}$

The cardiovascular demand on basketball referees has been observed in other studies, which showed that the average intensity varies from 73-79 percentage of heart rate (\%HR) ${ }^{8-10}$ It has also been observed that the $\% \mathrm{HR}$ of basketball referees did not change during the game. ${ }^{10}$ On the other hand, some athletes have shown differences between game periods in terms of the quantity of actions of certain intensities, heart rate (\%HR), blood lactate concentration ([lac]), and stoppage. ${ }^{6}$ In this sense, it is interesting to investigate a game in its different periods. In soccer, the average HR of the referees is approximately $160-165$ beats per minute (bpm) and, for the assistants, $140 \mathrm{bpm} ;{ }^{3}$ in futsal it is $146 \pm 13 \mathrm{bpm}$, which equates to $76 \pm 6 \% \mathrm{HR}^{7}$ and in handball it is $131 \pm 15 \mathrm{bpm}$, which equates to $68 \% \mathrm{HR}^{11}$

[lac] is also used to analyze the demands of sports on referees and athletes. There are analyses of referees in soccer, ${ }^{12}$ in which no significant differences were found between the [lac] at halftime and at the end of the game, and in futsal, ${ }^{7}$ in which no significant differences were found between the [lac] from before the start of the game, at halftime, and at the end of the game. Specifically in basketball, there are analyses of the [lac] of athletes, but none for referees. ${ }^{13-15}$

We highlight that none of these studies regarding the demands imposed on referees have compared them at different phases during the same competition, which may present different demands.

The aim of this study was to investigate the distance covered in matches by basketball referees, the number of interruptions, and referees $\% \mathrm{HR}$ and [lac] behavior in the different match periods (MPs) of different competition phases of the 2009-2010 Brazilian Basketball League (NBB). Knowing this information at different phases of the same competition may assist in planning referees' physical training during the competitive season.

\section{Methods}

\section{Subjects}

This study comprised a random sample of 18 referees (16 classified as international referees and two as national referees), with an average age of $40.06 \pm 6.93$ years, body mass of $85.28 \pm 11.12 \mathrm{~kg}$, and height of $1.78 \pm 0.05 \mathrm{~m}$, from the five regions of the country belonging to the official NBB. All referees underwent a medical evaluation before the study began and were allowed to practice physical exercise.

\section{Ethical considerations}

All volunteers were informed about the evaluations and signed a consent form approved by the ethics and research committee of the University of Campinas (UNICAMP) (protocol no 1008/2010).

\section{Procedures}

The 2009-2010 NBB Championship for adult males consisted of 182 games in the qualifying phase (QP), plus playoffs of five games preceding the final and playoffs of five games in the final phase (FP). We analyzed a random sample of 12 games, with four games in the QP, four games in the semifinal playoffs, and four games in the final playoffs. The refereeing procedures of the matches were those of the International Basketball Federation (FIBA), with three referees officiating each match, resulting in 36 data sets.

\section{Pre-match procedures}

Before the beginning of each match, the referees headed to the locker room for the preparation of the three data collection procedures, comprising collection of $25 \mu \mathrm{L}$ blood, calibration of the pedometer, and placement of the HR transmitter.

\section{Distance covered in a match}

To measure the distance covered, we used a pedometer (Digi-Walker, model SW 700; YAMAX Health and Sports, Inc, San Antonio, TX, USA) ${ }^{16}$ attached to the waist of each referee. Before each evaluation, an individual equipment calibration was performed with an average distance of ten paces. The distance covered was recorded at the end of each game quarter.

\section{Match interruptions}

For all games there are statistical analysis of the game actions, ie, shots of 2 or 3 points, free throws, assistance, etc. We considered all interruptions resulting from the referees' whistles, due to, for example, player errors, violations, fouls, and technical time-outs.

\section{Maximum $\mathrm{HR}\left(\mathrm{HR}_{\max }\right)$}

A week before the competition, a maximal multistage $20 \mathrm{~m}$ shuttle run test ${ }^{17}$ was applied to determine the $\mathrm{HR}_{\max }$ of 
referees. During testing, each referee used an HR monitor (Polar ${ }^{\circledR}$ Team System; Polar Electro Oy, Kempele, Finland) that was programmed to record HR every 5 seconds, and the $\mathrm{HR}_{\max }$ was considered the highest value obtained in the last stage reached in the test.

\section{HR during matches}

HR values during a match were obtained with the Polar ${ }^{R}$ Team System HR monitor, programmed to record HR every 5 seconds. At the same time, a digital timer (Casio ${ }^{\circledR}$, Tokyo, Japan) was activated to ascertain and record the time of the beginning and end of each quarter and to later synchronize with the data of the monitors.

\section{[lac] in matches}

For blood collection, the referees remained seated for 10 minutes, then we collected blood samples of $25 \mathrm{~mL}$ from earlobe capillaries. The samples were calibrated and heparinized in accordance with standard biosecurity practice. Immediately after the collection of each sample, blood was analyzed with the Accutrend Plus (Roche ${ }^{\circledR}$, Mannheim, Germany). Five minutes after the end of the first half (during halftime), and again 5 minutes after the end of the match, the same collection and analysis procedures were conducted.

\section{Statistical analysis}

For statistical analysis, SPSS software (v 16.0; IBM Corporation, Armonk, NY, USA) was used. Data are expressed as mean, median, standard deviation and confidence interval (CI 95\%). The distribution of data regarding normality was checked by the Shapiro-Wilk test. For quantitative variables with normal distribution, mean and standard deviation data were presented, and, for variables with non-normal distribution, median and $95 \%$ CI data were presented. For comparisons between quarters, we used analysis of variance (ANOVA) for repeated measures and nonparametric Friedman test. When necessary, the post hoc Bonferroni test was applied. For comparisons between phases, ANOVA was used, and, when necessary, the post hoc Tukey's test and the Kruskal-Wallis test were applied. When necessary, the post hoc Bonferroni test was applied. The significance level for all analyses was $P<0.05$.

\section{Results}

\section{Distance covered increases throughout competition phases}

The distances covered by the referees in the matches are shown, in kilometers, in Table 1. Data were obtained with the pedometer, for each referee, in each of the matches.
Table I Comparison of the distances covered by referees $(\mathrm{km})$ between match periods and phases of the competition

\begin{tabular}{|c|c|c|c|}
\hline \multirow[t]{2}{*}{ MP } & \multicolumn{3}{|c|}{ Competition phase } \\
\hline & $\begin{array}{l}\text { Qualifying } \\
N=9\end{array}$ & $\begin{array}{l}\text { Semifinal } \\
\mathbf{N}=I I\end{array}$ & $\begin{array}{l}\text { Final } \\
N=12\end{array}$ \\
\hline Ist MP & $\mathrm{I} .00(0.8 \mathrm{I}-\mathrm{I} .20)$ & $1.23(1.09-1.37)$ & $1.45(1.39-1.53)^{+, \pi}$ \\
\hline 2nd MP & $1.00(0.86-1.14)$ & $1.21(1.10-1.32)$ & $1.57(1.46-1.68)^{* . \#}$ \\
\hline 3th MP & I.0I (0.75-I.27) & $1.10(0.97-1.23)$ & $1.44(1.33-1.54)^{*, \#}$ \\
\hline 4th MP & $1.00(0.80-1.20)$ & $1.43(1.22-1.64)^{*}$ & I.7। $(1.54-1.89)^{*, \mp}$ \\
\hline Entire match & $4.02(3.26-4.77)$ & $4.97(4.74-5.21)^{*}$ & $6.17(5.90-6.45)^{\text {*.\# }}$ \\
\hline \multicolumn{4}{|l|}{$N=8$} \\
\hline \multicolumn{4}{|c|}{$\begin{array}{l}\text { Notes: }{ }^{\dagger} \text { Difference significant in relation to the qualifying phase (ANOVA, } P<0.05 \text { ); } \\
\text { "difference significant in relation to the semifinal phase (ANOVA, } P<0.05 \text { ); } \\
\text { *difference significant in relation to the qualifying phase (Kruskal-Wallis, } P<0.05 \text { ); } \\
\text { "difference significant in relation to the semifinal phase (Kruskal-Wallis, } P<0.05 \text { ); } \\
{ }^{\mp} \text { difference significant between } 3 \text { rd and 4th MPs (ANOVA for repeated measures, } \\
P<0.05 \text { ). Data are expressed in kilometers. }\end{array}$} \\
\hline
\end{tabular}

The distance covered by all referees in the QP was significantly lower than that in the semifinal phase (SP) and FP only for the 4th MP (QP $=1.00,95 \%$ CI: $0.80-1.20$; $\mathrm{SP}=1.43,95 \% \mathrm{CI}: 1.22-1.64 ; \mathrm{FP}=1.71,95 \% \mathrm{CI}: 1.54-1.89$; $P=0.012$ and $P=0.0001$, respectively). In the FP, the distance covered was significantly higher than in the QP and SP for the 1st MP (QP $=1.00,95 \%$ CI: $0.81-1.20 ; \mathrm{SP}=1.23,95 \%$ CI: $1.09-1.37 ; \mathrm{FP}=1.45,95 \% \mathrm{CI}: 1.39-1.53 ; P=0.0001$ and $P=0.004$, respectively) and $3 \mathrm{rd} \mathrm{MP}(\mathrm{QP}=1.01,95 \%$ CI: $0.75-1.27$; $\mathrm{SP}=1.10,95 \% \mathrm{CI}: 0.97-1.23$; FP $=1.44$, 95\% CI: $1.33-1.54 ; P=0.001$ and $P=0.004$, respectively). The distance covered was significantly higher during the phases of the 2nd MP (QP $=1.00,95 \%$ CI: $0.86-1.14$; $\mathrm{SP}=1.21,95 \% \mathrm{CI}: 1.10-1.32 ; \mathrm{FP}=1.57,95 \% \mathrm{CI}: 1.46-1.68$; $\mathrm{QP}$ versus [vs] SP, $P=0.025$; QP vs FP, $P=0.0001$; SP vs $\mathrm{FP}, P=0.0001)$ and in the entire match $(\mathrm{QP}=4.02,95 \% \mathrm{CI}$ : 3.26-4.77; $\mathrm{SP}=4.97,95 \% \mathrm{CI}: 4.74-05.21 ; \mathrm{FP}=6.17,95 \%$ CI: 5.90-6.45; QP vs SP, $P=0.005$; QP vs FP, $P=0.004$; FP vs SP, $P=0.001)$.

By comparing the periods within each phase, we found a greater distance was covered in the 4th MP in relation to the 3rd MP $(P=0.029)$ during the FP.

\section{Number of interruptions did not differ between periods}

The number of interruptions was obtained by statistical analysis of the matches, with respect to errors, violations, fouls, and technical time-outs. The number of interruptions that occurred in the matches did not differ between the periods (1st MP to 4th MP), in any of the phases of the competition (QP, $P=0.768$; SP, $P=0.335$; and FP, $P=0.392$ ), (1 st MP, $P=0.345 ; 2$ nd MP, $P=0.356$; 3rd MP, $P=0.451$; 4th MP, 
$P=0.572$; and entire match, $P=0.444)$. The mean \pm standard deviation values were $70.33 \pm 10.26,77.00 \pm 4.24$, and $78.75 \pm 6.95$ for QP, SP, and FP, respectively.

\section{$H R$ decreased in the final quarters of the SP and FP}

The HR values obtained in the matches were transformed into $\% \mathrm{HR}$, regarding the $\mathrm{HR}_{\max }$ obtained in the maximal multistage $20 \mathrm{~m}$ shuttle run test ${ }^{17}$ (Table 2). By comparing match periods within each phase, we found higher $\% \mathrm{HR}$ in the $1 \mathrm{st}$ MP relative to the $3 \mathrm{rd}$ MP $(P=0.013)$ and in the 2 nd MP relative to the $3 r d(P=0.001)$ and 4th $(P=0.01) \mathrm{MPs}$, in the SP $(1 \mathrm{st} \mathrm{MP}=76.29 \pm 7.19$; 2nd $\mathrm{MP}=78.00 \pm 7.27 ; 3 \mathrm{rd} \mathrm{MP}=73.21 \pm 6.56 ; 4$ th $\mathrm{MP}=74.01 \pm 6.93)$. In the FP, the 4th MP presented lower \%HR compared to the $1 \mathrm{st}(P=0.018)$ and 2 nd $(P=0.014)$ MPs $(1$ st $\mathrm{MP}=79.94 \pm 7.12 ; 2 \mathrm{nd} \mathrm{MP}=79.73 \pm 6.87 ; 3 \mathrm{rd}$ $\mathrm{MP}=77.83 \pm 6.26 ; 4$ th $\mathrm{MP}=76.73 \pm 6.35)$. There were no significant differences between the periods in the QP. \%HR was observed to increase as competition rounds progressed, but there were no significant differences between the competition phases (1st MP, $P=0.299$; 2nd MP, $P=0.089$; 3rd MP, $P=0.134$; 4th MP, $P=0.119$; and entire match, $P=0.331)$ (Table 2).

\section{[lac] did not show significant changes between periods}

The [lac] of each referee $(\mathrm{mM})$ was obtained before, during (in the halftime), and after each match. We observed data normality using the Shapiro-Wilk test, and we did not observe a significant difference between the competition phases (QP, $P=0.311$; SP, $P=0.620$; and FP, $P=0.309$ ) nor between [lac] measurement times (before, $P=0.195$; halftime, $P=0.468$; and after, $P=0.185$ ) (Table 3 ).

Table 2 Comparison of \%HR of referees in different MPs and phases of competition

\begin{tabular}{|c|c|c|c|}
\hline \multirow[t]{2}{*}{ MP } & \multicolumn{3}{|c|}{ Competition phase } \\
\hline & $\begin{array}{l}\text { Qualifying } \\
N=9\end{array}$ & $\begin{array}{l}\text { Semifinal } \\
\mathbf{N}=\text { I I }\end{array}$ & $\begin{array}{l}\text { Final } \\
N=12\end{array}$ \\
\hline Ist MP & $74.15 \pm 12.00$ & $76.29 \pm 7.19$ & $79.94 \pm 7.12$ \\
\hline 2nd MP & $72.23 \pm 10.67$ & $78.00 \pm 7.27$ & $79.73 \pm 6.87$ \\
\hline 3th MP & $71.05 \pm 10.93$ & $73.21 \pm 6.56^{* \#}$ & $77.83 \pm 6.26$ \\
\hline 4th MP & $70.07 \pm 9.48$ & $74.01 \pm 6.93^{\#}$ & $76.73 \pm 6.35^{*, \#}$ \\
\hline Entire match & $71.66 \pm 10.40$ & $75.22 \pm 6.80$ & $78.39 \pm 6.52$ \\
\hline
\end{tabular}

Notes: *Difference significant compared to the Ist MP (ANOVA for repeated measures, $P<0.05$ ); ${ }^{*}$ difference significant compared to the 2nd MP (ANOVA for repeated measures, $P<0.05)$. Data are expressed in \%HRmax.

Abbreviations: \%HRmax, percentage of heart rate; ANOVA, analysis of variance; MP, match period.
Table 3 Blood lactate concentration $(\mathrm{mM})$ of the referees at different times of the match and phases of competition, with no significant difference

\begin{tabular}{llll}
\hline Match & \multicolumn{3}{l}{ Competition phase } \\
\cline { 2 - 4 } time & Qualifying & Semifinal & Final \\
& $\mathbf{N}=\mathbf{6}$ & $\mathbf{N}=\mathbf{7}$ & $\mathbf{N}=\mathbf{I}$ I \\
\hline Beginning & $3.08 \pm 0.69$ & $2.24 \pm 0.69$ & $2.94 \pm 0.84$ \\
Halftime & $3.07 \pm 0.58$ & $2.09 \pm 1.20$ & $2.93 \pm 0.84$ \\
End & $2.53 \pm 1.06$ & $3.37 \pm 0.67$ & $2.86 \pm 0.85$ \\
\hline
\end{tabular}

Note: Data are expressed in $\mathrm{mM}$.

\section{Discussion}

To our knowledge, this is the first study to evaluate the demands on basketball referees during each match in the different phases of a competition, as to the distance covered, $\% \mathrm{HR},[\mathrm{lac}]$, and interruptions. The main finding of this study is that there was an increase in the distance covered over the phases of the competition and a decrease in $\% \mathrm{HR}$ for the periods of the match. Knowledge of the demands on referees in basketball matches enables the planning of training toward proper performance. Knowing that the distances covered in the matches increase throughout the phases of the competition demonstrates the need for referees to improve their physical fitness.

The only available study analyzing the distance covered in matches is from 2001, involving the two-referee system and with matches divided into two periods of 20 minutes each. ${ }^{5}$ This study found mean values of distance covered of $2.45 \pm 0.22 \mathrm{~km}$ and $2.51 \pm 0.23 \mathrm{~km}$ for the first and second periods, respectively. However, it did not compare the distance covered between the phases of the competition. In a study of the demands of futsal, ${ }^{7}$ involving analysis of data every 10 minutes of play, there was a decrease in the distance covered by the referees and a decrease in the amount of activity (as for the first 10 minutes referees did more intense activities then others). The reduction in the distance covered and the number of intense activities was attributed to the presence of fatigue arising from the game. It should be noted that, unlike basketball, futsal is played in two periods of 30 minutes each and not in four periods of 10 minutes each. In this case, the onset of fatigue may be different.

In our study, the increase in distances covered throughout the phases of the competition was not accompanied by increased \%HR or [lac]. Regarding the different periods, in the respective phases, the relationship between distance covered and $\% \mathrm{HR}$ was reversed. We speculate that this result may have been as a result of the duration of interruptions of matches, because, although the number of interruptions remained the same, their duration, which was not analyzed 
in this study, may have increased, thus providing longer pauses between periods of action. It has been verified by Abdelkrim et $\mathrm{al}^{6}$ that stoppage time is significantly higher in the last period of a basketball game than in any other (1st MP, $488 \pm 32$ seconds; 2nd MP, $554 \pm 44$ seconds; 3rd MP, $590 \pm 46$ seconds; and 4th MP, $766 \pm 55$ seconds), which may result in lower \% $\mathrm{HR}$ and [lac] in athletes.

The $\% \mathrm{HR}$ values found in our study are similar to those found ( 73 and $78.7 \pm 8.8 \% \mathrm{HR}$ ) by Leicht, ${ }^{8,9}$ also in basketball referees, but, in our study, comparison between periods shows a significant decrease of $\% \mathrm{HR}$ among the periods in the SP and FP. Leicht's studies were conducted only during the QP of a national competition ${ }^{8}$ and during an international tournament, preparatory for the 2004 Olympic Games. ${ }^{9}$ There were also no significant differences of $\% \mathrm{HR}$ between the periods in the QP in our study. On the other hand, unlike other studies, we also analyzed the SP and FP, finding significant differences in $\% \mathrm{HR}$. These findings demonstrate the importance of investigating the effort required during different phases of the same competition.

Our values, and others, characterize the intensity of efforts as moderate and vigorous, ${ }^{18}$ thus, reinforcing the importance of specific and appropriate physical training to ensure highquality refereeing.

The [lac] did not change during the match; however, the [lac]s from the beginning of the game were relatively high $(3.08 \pm 0.69$ in $\mathrm{QP} ; 2.24 \pm 0.69$ in $\mathrm{SP}$; and $2.94 \pm 0.84$ in FP). These results were likely as a result of stress, anxiety, pressure, and responsibility of referees in the development of the game. It is known that [lac] is influenced by the sympathetic nervous system, and it has been verified that psychosocial stress can increase [lac] by up to $47 \%$, which is attributed to increases in epinephrine and drenocorticotropic hormone. ${ }^{19}$ Krustrup and Bangsbo ${ }^{12}$ found higher [lac] concentrations in soccer referees than those found in our study $(4.8 \pm 0.4 \mathrm{mM}$ in halftime and $5.0 \pm 0.5 \mathrm{mM}$ at the end of the match), but the distance covered by the referees was greater ( $10.07 \pm 0.13 \mathrm{~km})$, as was the game duration (90 minutes). For futsal referees, lower [lac] was found at rest $(1.0 \pm 0.3 \mathrm{mM})$, in halftime $(2.0 \pm 0.8 \mathrm{mM})$, and after a match $(1.5 \pm 0.5 \mathrm{mM})$, but there were fewer intense activities at the end of the game. ${ }^{7}$ In these studies, ${ }^{7,12}$ no significant differences were found between the periods of the match. In basketball players, ${ }^{6}$ we observed an increase in [lac], in relation to the beginning of the game, and a reduction in [lac] at the end of the game, in relation to in halftime. The decrease at the end of the game was attributed to fewer intensive activities and longer durations of stoppage times in the last quarter. These two factors, which were not controlled in our study, may have influenced the [lac] found in our study.

We believe that further studies are necessary to determine the characteristics and speeds of referees' movements. Further studies could also examine the durations of interruptions to establish this influence on physical demands imposed on referees during a match. We also understand that the differences related to the phases of the competition open perspectives for further similar studies in other sports, as all studies to date have analyzed only the demands at a certain stage of the same competition. This information could aid the planning of specific physical training for referees. For example, it has been shown by Helgerud et $\mathrm{al}^{20}{ }^{20}$ in a study involving young soccer athletes, that the interval training of $4 \times 4$ minutes at 90-95\%HR, interspersed with 3 minutes of jogging, twice a week for 8 weeks, increased the distance covered and the performance of athletes in a game.

Such information is important for planning the training and optimizing the performance of referees in matches, which can ensure successful refereeing. ${ }^{3,4}$ Basing referee training only on distances covered during a QP could result in lower performances in the SP and FP.

This study aimed to be a guide for planning the training of basketball referees over the course of a season. The findings show the need to increase a referee's capacity to support higher volumes of movements in matches as the competition comes close to the FP. There is a need for improvement in aerobic capacity, due to intermittent actions, varying speeds, and direction changes, but with the maintenance of an average intensity determined by the $\% \mathrm{HR}$ close to that found in our study.

\section{Conclusion}

Our study shows that there is an increase in the distance covered by basketball referees throughout the phases of a competition, and that this is not accompanied by increased physical demands, as shown by number of interruptions, $\% \mathrm{HR}$, and [lac].

\section{Acknowledgments}

We would like to thank the Brazilian Basketball League and its referee department.

\section{Author contributions}

JPB and PCM contributed substantially to the conception and design of the study, staff coordination, and critical revision of the manuscript for important intellectual content and final approval of the version to be published. JFD, VB, CRC, and 
LAM were responsible for data acquisition and writing of the manuscript. AMM and MTNS reviewed the data and provided statistical and scientific input.

\section{Disclosure}

The authors report no conflicts of interest in this work.

\section{References}

1. Crisafulli A, Melis F, Tocco F, Laconi P, Lai C, Concu A. External mechanical work versus oxidative energy consumption ratio during a basketball field test. J Sports Med Phys Fitness. 2002;42:409-417.

2. Ziv G, Lidor R. Physical attributes, physiological characteristics, on-court performances and nutritional strategies of female and male basketball players. Sports Med. 2009;39:547-568.

3. Reilly T, Gregson W. Special populations: the referee and assistant referee. J Sports Sci. 2006;24:795-801.

4. Weston M, Castagna C, Impellizzeri FM, Rampinini E, Abt G. Analysis of physical match performance in English Premier League soccer referees with particular reference to first half and player work rates. $J$ Sci Med Sport. 2007;10:390-397.

5. Cestaro Júnior S, Molina R, Denadai BS. Análise do deslocamento do árbitro em quadra no primeiro e segundo período da partida de basquetebol. [Analysis of the referee's displacement on court in the first and second match periods]. Revista Treinamento Desportivo. 2001;6:31-37. Portuguese.

6. Ben Abdelkrim N, El Fazaa S, El Ati J. Time-motion analysis and physiological data of elite under-19-year-old basketball players during competition. Br J Sports Med. 2007;41(2):69-75.

7. Rebelo AN, Ascensão AA, Magalhães JF, Bischoff R, Bendiksen M, Krustrup P. Elite futsal refereeing: activity profile and physiological demands. J Strength Cond Res. 2011;25:980-987.

8. Leicht AS. Cardiovascular stress on an elite basketball referee during national competition. Br J Sports Med. 2004;38:E10.
9. Leicht AS. Physiological demands of basketball refereeing during international competition. J Sci Med Sport. 2008;11:357-360.

10. Holland JC, Cherry RB. Aerobic capacity, body composition, and heart rate response curves of high school basketball officials. J Sports Med Phys Fitness. 1979;19:63-72.

11. da Silva JF, Castagna C, Carminatti LJ, Foza V, Guglielmo LG, de Oliveira FR. Physiological demands of team-handball referees during games. J Strength Cond Res. 2010;24(7):1960-1962.

12. Krustrup P, Bangsbo J. Physiological demands of top-class soccer refereeing in relation to physical capacity: effect of intense intermittent exercise training. J Sports Sci. 2001;19:881-891.

13. McInnes SE, Carlson JS, Jones CJ, McKenna MJ. The physiological load imposed on basketball players during competition. J Sports Sci. 1995;13:387-397.

14. Rodríguez-Alonso M, Fernández-García B, Pérez-Landaluce J, Terrados N. Blood lactate and heart rate during national and international women's basketball. J Sports Med Phys Fitness. 2003;43:432-436.

15. Narazaki K, Berg K, Stergiou N, Chen B. Physiological demands of competitive basketball. Scand J Med Sci Sports. 2009;19:425-432.

16. Crouter SE, Schneider PL, Karabulut M, Bassett DR Jr. Validity of 10 electronic pedometers for measuring steps, distance, and energy cost. Med Sci Sports Exerc. 2003;35:1455-1460.

17. Léger LA, Mercier D, Gadoury C, Lambert J. The multistage 20 metre shuttle run test for aerobic fitness. J Sports Sci. 1988;6:93-101.

18. Garber CE, Blissmer B, Deschenes MR, et al; American College of Sports Medicine. American College of Sports Medicine position stand. Quantity and quality of exercise for developing and maintaining cardiorespiratory, musculoskeletal, and neuromotor fitness in apparently healthy adults: guidance for prescribing exercise. Med Sci Sports Exerc. 2011;43:1334-1359.

19. Kubera B, Hubold C, Otte $S$, et al. Rise in plasma lactate concentrations with psychosocial stress: a possible sign of cerebral energy demand. Obes Facts. 2012;5(3):384-392.

20. Helgerud J, Engen LC, Wisloff U, Hoff J. Aerobic endurance training improves soccer performance. Med Sci Sports Exerc. 2001;33(11): 1925-1931.
Open Access Journal of Sports Medicine

\section{Publish your work in this journal}

Open Access Journal of Sports Medicine is an international, peer-reviewed, open access journal publishing original research, reports, reviews and commentaries on all areas of sports medicine. The manuscript management system is completely online and includes a very quick and fair peer-review system.

\section{Dovepress}

Visit http://www.dovepress.com/testimonials.php to read real quotes from published authors. 